\title{
Investing in the future
}

Ten years ago, the Irish Journal of Psychological Medicine explicitly renewed its commitment to the central objectives of the Journal: disseminating the results of original scientific research to a national and international readership; expressing the unique identity of Irish psychiatry; and underscoring the important cross-cultural differences in psychiatry within and beyond these islands. ${ }^{1}$ At that time, projected developments for the future included attracting more research papers from Ireland and abroad; increasing international readership; and continuing to develop the advantages associated with smaller journals, including rapid turnaround times, flexible editorial policies and user-friendliness.

Over the past 10 years, there has been considerable progress in many of these areas. More national and international research papers are being submitted and published; the Journal now has a circulation of 2,200 copies in 54 countries; the format of the Journa/ has been substantially revised; and there is increased focus on user-friendliness. In particular, a Journa/ website (www.ijpm.org) has been developed and now offers full-text open-access to recent issues of the Journal. These developments are, of course, dependent on the support of the Journals readers, peer-reviewers and all who submit papers, both from Ireland and abroad.

The field of medical publication is, however, constantly changing, and current areas of particular controversy relate to evolving forms of electronic communication in medical publishing ${ }^{2}$ and various initiatives moving towards openaccess publishing of medical research. ${ }^{3}$ At the Irish Journal of Psychological Medicine, too, there are several new initiatives planned, aimed at ensuring that the content and format of the Journa/ remain as relevant, rigorous and reliable as possible.

In the first instance, the Journa/ will continue to seek out and publish high-quality original research papers, from Ireland and abroad, and will aim to offer an efficient and rigorous process of peer review as part of this process. To this end, it is hoped to introduce a 'fast-track' peer-review option, to facilitate the timely publication of papers that have immediate relevance or urgent importance. The Journa/ website will also be further developed and expanded in the coming years.

In addition, the Journal has recently appointed its first 'trainee editor.' The position of trainee editor was created with a view to:

Brendan D Kelly, MB MD MSc MRCPsych, Trainee Editor of the Irish Journal of Psychological Medicine, South Meath Mental Health Services, Dunshaughlin Health Care Unit, Main Street, Dunshaughlin, Co Meath, Ireland. (a) Increasing the involvement of psychiatry trainees in the submission of original research papers, audit papers, and other articles to the Journal;

(b) Optimising the relevance of the Journal's content to trainees, by commissioning review papers on topics of relevance to trainees preparing for the membership examination of the Royal College of Psychiatrists (MRCPsych); and

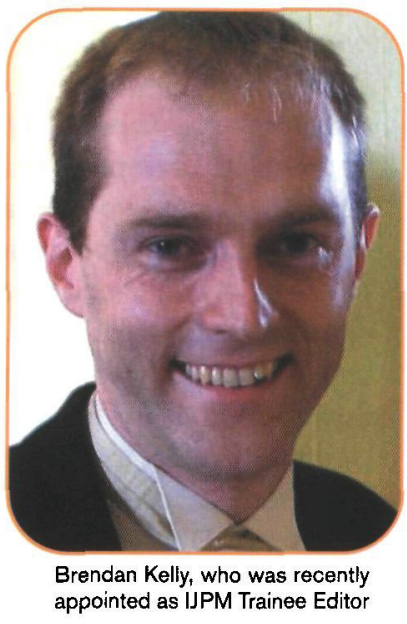

(c) Involving the trainee editor in the wider editorial process at the Journal. Trainees in psychiatry are now actively invited to submit both original research papers and audit reports to the Journal.

Medical journals play an important role in shaping medical knowledge. ${ }^{4}$ Medical journals also play a critical role in informing evidence-based practice, developing health policy, and underpinning training programmes in healthcare disciplines. These are particularly exciting times in the fields of psychiatry and mental health, especially with the development of more evidence-based approaches to treatment and continued advances in psychiatric research, especially in the fields of psychiatric genetics, neuroimaging and psychiatric epidemiology.

In Ireland, in particular, there are considerable changes under way within psychiatry: the Mental Health Act 2001 is currently being introduced across the mental health services; a major revision of mental health policy is due to be published in 2005; and the Irish health service in general is undergoing a period of accelerated reform, especially in terms of financial management structures and human resources management.

It is the aim of the Irish Journal of Psychological Medicine to keep apace and ahead of these changes; to provide a critical and constructive voice, both in Ireland and abroad; and to help inform the scientific and medical basis of developments in psychiatric practice in the future. We look forward to your assistance and involvement in this process.

References

1. Lawlor BA. Quo vadis? Irish Journal of Psychological Medicine 1994; 11: 107. 2. Fletcher $\mathrm{RH}$, Fletcher $\mathrm{SW}$. The future of medical journals in the western world. Lancet. 1998; 352: Suppl 2: SII30-3.

3. Horton R. 21st-century biomedical journals: failures and futures, Lancet 2003; 362 1510-1512.

4. Vandenbroucke JP. Medical journals and the shaping of medical knowledge. Lancet 1998; 352: 2001-2006 